\title{
Ionizing Irradiation Using Electron Beam to Control Importation of Biothreat Agents in Geranium Cuttings Inhibits Rooting
}

\author{
Wayne A. Mackay ${ }^{1,2}$ \\ Texas A \& M University, TAES-Dallas, 17360 Coit Road, Dallas, TX \\ 75252-6599
}

\section{Brent Pemberton \\ Texas A \& M University, TAES-Overton, 1710 North Highway 3053, P.O. Box 200, Overton, TX 75684}

\author{
Joseph Maxim and Suresh D. Pillai \\ National Center for Electron Beam Research, Texas A \& M University, \\ Kleberg Center, Room 418, College Station, TX 77843-2472
}

Additional index words. Pelargonium $\times$ hortorum, disinfestation, pathogen suppression, asexual propagation, disease agents

\begin{abstract}
Pelargonium $\times$ hortorum 'Tango Dark Red', 'Tango Pink', 'Americana Red', and 'Rocky Mountain Lavender' unrooted cuttings were subjected to Electron beam (E-beam) irradiation at 0 (control, no treatment), $0.61 \pm 0.04,0.83 \pm 0.07$, or $1.02 \pm 0.01$ $\mathrm{kGy}($ mean $\pm \mathrm{SE}, \mathrm{n}=4$ ) in Expt. 1 and 0 (control, no treatment), $0.08 \pm 0.00,0.16 \pm 0.00$, $0.31 \pm 0.00$, or $0.57 \pm 0.02 \mathrm{kGy}($ mean $\pm \mathrm{SE}, \mathrm{n}=4$ ) in Expt. 2. Cuttings exposed to E-beam irradiation other than the control treatment did not root or form callus and exhibited a change in leaf color from green to red and eventually yellow. Our results suggest that the use of ionizing irradiation for preventing the accidental importation of biothreat agents through unrooted Pelargonium cuttings is not feasible.
\end{abstract}

Ionizing irradiation such as Electron beam (E-beam) irradiation is used to destroy microbial pathogens in food (Smith and Pillai, 2004). In addition to food, E-beam irradiation can be used for sterilizing pharmaceutical products, curing polymers, and for phytosanitary applications to prevent the importation of dangerous insects and pests. We hypothesized that E-beam irradiation could be used for the disinfestation of Pelaragonium cuttings to allow importation of cuttings produced offshore without the risk of introducing disease agents that currently are not present in the United States. Experiments were conducted to assess the feasibility of using E-beam irradiation doses of $1 \mathrm{kGy}$ or less as a disinfestation tool for geranium cuttings following current USDAAPHIS regulations, which restrict the use of ionizing radiation to $1 \mathrm{kGy}$ or less for phytosanitary applications (APHIS, 2002).

\footnotetext{
Received for publication 19 Oct. 2007. Accepted for publication 9 Jan. 2008.

${ }^{1}$ Current address: University of Florida, Mid-Florida Research and Education Center, IFAS, 2725 South Binion Road, Apopka, FL 32703-8504.

${ }^{2}$ To whom reprint requests should be addressed; e-mailwmackay@ufl.edu
}

a mist bench containing $50 \%$ perlite $/ 50 \%$ vermiculite rooting media with bottom heat $\left(24 \pm 2{ }^{\circ} \mathrm{C}\right)$. Mist frequency was controlled by an electronic leaf (Phytronics, Earth City, MO). In Expt. 2, the same procedure was followed except that the treatment dosages were 0 (control no treatment), $0.08 \pm 0.00$, $0.16 \pm 0.00,0.31 \pm 0.00$, or $0.57 \pm 0.02 \mathrm{kGy}$ (mean \pm SE, $n=4)$. The cuttings were checked for rooting at $14 \mathrm{~d}$ for both experiments. In Expt. 1, the cuttings were pulled on day 25 after sticking, and rooting data were collected. In Expt. 2, the cuttings were pulled on day 17 to collect final rooting data. Data consisted of number of roots and length of roots.

\section{Results and Discussion}

In both experiments, $100 \%$ of the cuttings of the four cultivars in the control treatment rooted within $14 \mathrm{~d}$. However, none of the cuttings treated with E-beam irradiation at any dosage exhibited any sign of callusing or rooting at day 25 for Expt. 1 or day 17 for Expt. 2. Additionally, the leaves turned a crimson red after treatment with E-beam irradiation and there was no growth of the shoot apex (Fig. 1). The rate and intensity at which the leaves turned red was directly proportional to the dosage received by the cuttings with the cuttings treated with the highest dosage (1.02 kGy) turning red within 1 week of the treatment (data not shown). The loss of chlorophyll and exhibition of red pigments did not occur in any of the control cuttings and indicates that the E-beam irradiation was detrimental to the health of the cuttings.

Studies have reported that ionizing radiation can affect chlorophyll content and photosynthesis. Conter et al. (1986) showed that in the cyanobacterium Synechococcus lividus, very low ionizing radiation doses caused an earlier onset of photosynthesis as evidenced by an increase in pigment content and enhancement of glyceraldehyde-3-phosphate dehydrogenase. The authors suggested that radiostimulation was related to activation of enzymes protecting against peroxides induced under oxidative circumstances and to the activation of a glucose catabolism through the oxidative pentose phosphate pathway. Jo et al. (2001) reported that chlorophyll b is susceptible to ionizing irradiation. Jovanić and Dramićanin (2003) showed that at doses as low as $0.003 \mathrm{kGy}$ ( 3 Gy), ionizing radiation was capable of altering the fluorescence spectra [fluorescence intensity ratio (FIR) at 695 and $735 \mathrm{~nm}$ ] of pumpkin leaves. They believed that the spectral difference was manifested by a decrease of FIR as a result of a change in chlorophyll luminescence possibly resulting from an increase of chlorophyll concentration during the recovery process of the plant. However, Fan and Thayer (2001) reported that ionizing irradiation had no effect on chlorophyll content in alfalfa sprouts, whereas Mukhin and Sal'kova (1961) reported that potato tubers exposed to ionizing radiation lost their ability to form chlorophyll. In our 


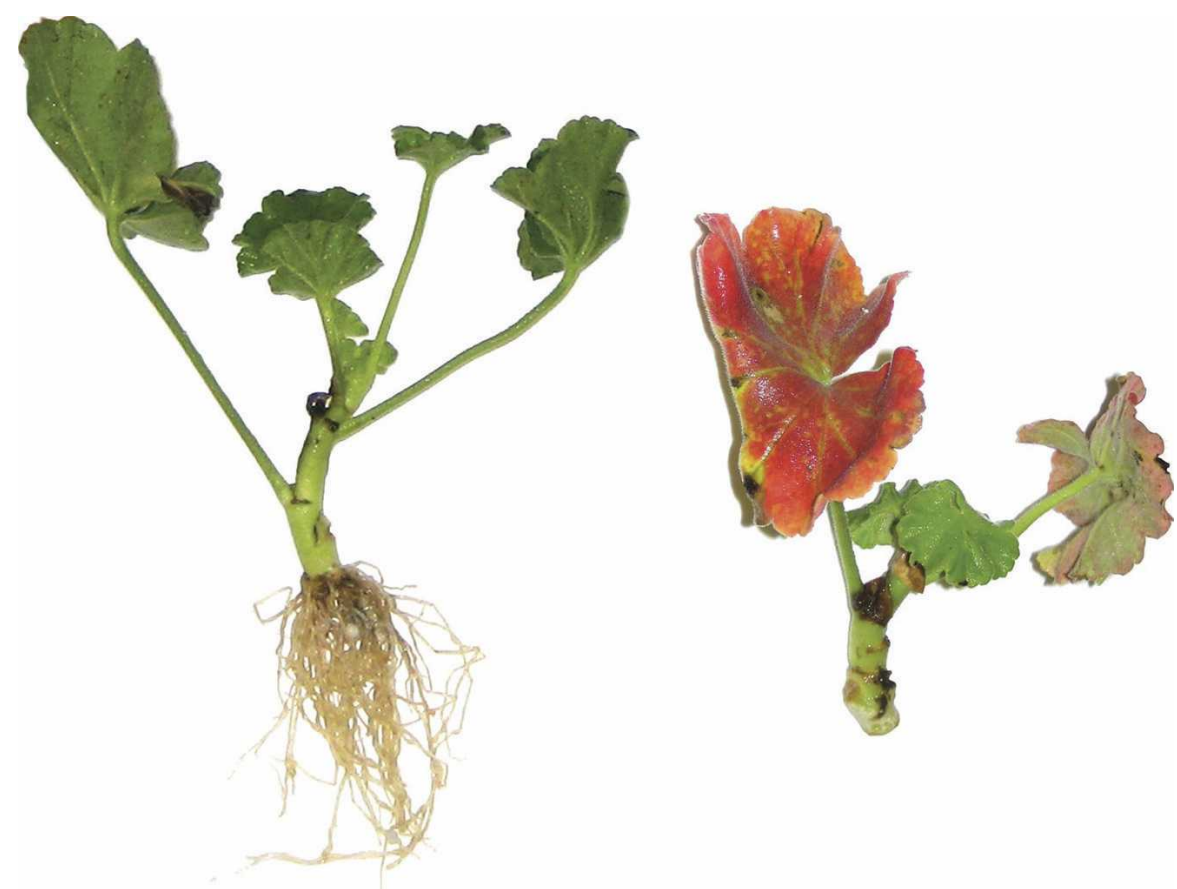

Fig. 1. Pelargonium cuttings treated with electron beam irradiation; $0.0 \mathrm{kGy}$ (control) on left and $0.61 \pm 0.04 \mathrm{kGy}$ on right.

experiments, the loss of chlorophyll and the lack of rooting or callus formation in treated cuttings indicate that pelargonium is very sensitive to ionizing irradiation.

In conclusion, because the pelargonium cuttings did not root at doses that were significantly below the current USDA-APHIS regulations for phytosanitary applications, this indicates that the use of ionizing irradiation for preventing the accidental importation of biothreat agents through unrooted Pelargonium cuttings is not feasible.

\section{Literature Cited}

[APHIS] U.S. Dept. Agr., Animal and Plant Health Inspection Service. 2002. Irradiation phytosanitary treatment of imported fruits and vegetables. Federal Register 67:65016-65029.

Conter, A., D. Dupouy, C. Delteil, and H. Planel. 1986. Influence of very low doses of ionizing radiation on Synechococcus lividus metabolism during the initial growth phase. Arch. Microbiol. 144:286-290.

Fan, X. and D.W. Thayer. 2001. Quality of irradiated alfalfa sprouts. J. Food Prot. 64:1574-1578.

Jo, C., J.-W. Lee, and M.-W. Byun. 2001. Short communication of novel application of food irradiation. J. Food Science and Nutrition 6:253-256.

Jovanić, B.R. and M.D. Dramićanin. 2003. In vivo monitoring of chlorophyll fluorescence response to low-dose $\gamma$-irradiation in pumpkin (cucurbita pepo) leaves. Luminescence 18:274-277.

Mukhin, E.N. and E.G. Sal'kova. 1961. The biosynthesis of chlorophyll in reserve depots in connection with the action of ionizing radiation. Dokl. Akad. Nauk SSSR 137:976979.
Smith, J.S. and S.D. Pillai. 2004. Irradiation and food safety. Science status summary. Food Technol. 58:48-55. 